nephron

Practice
Nephron 2016;134:183-190

DOI: $10.1159 / 000447979$
Received: March 21, 2016

Accepted: June 23, 2016

Published online: August 10, 2016

\title{
Oliguria and Biomarkers of Acute Kidney Injury: Star Struck Lovers or Strangers in the Night?
}

\author{
Georg F. Lehner $^{a}$ Lui G. Forni ${ }^{b}$ Michael Joannidis $^{a}$ \\ ${ }^{a}$ Division of Intensive Care and Emergency Medicine, Department of Internal Medicine, Medical University

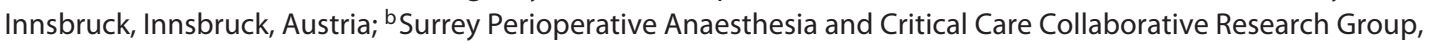 \\ Royal Surrey County Hospital NHS Foundation Trust and School of Health Sciences, Faculty of Health and Medical \\ Sciences, University of Surrey, Guildford, UK
}

\section{Key Words}

Oliguria · Acute kidney injury · Biomarker · Urinary output er signal and the urinary output are intimately linked and this review is intended to elucidate the relationship between the two.

\section{Oliguria as Biomarker}

The definition of oliguria associated with acute renal failure appeared more than 200 years ago as described by the English physician Heberden [1]. However, the systematic inclusion in the definition of AKI did not occur until the description of the risk, injury, failure, loss, endstage renal disease criteria, where a urinary output of less than $0.5 \mathrm{ml} / \mathrm{kg} / \mathrm{h}$ for more than $6 \mathrm{~h}$ was introduced as an alternative criterion to a rise in serum creatinine [2]. This definition has remained consistent in the latest Kidney Disease Improving Global Outcomes (KDIGO) guidelines defining AKI [7]. Although the descriptions of urinary output and elevations in serum creatinine have been considered of equal importance as indicators of AKI in

Oliguria is one of the oldest 'biomarkers' of renal in jury $[1,2]$. However, the utility of oliguria as a predictor of acute kidney injury (AKI) in hospitalized patients is limited by its relative sensitivity but poor specificity $[2,3]$. To improve both the prediction of, and diagnosis of AKI, several biomarkers have been described over the last 2 decades reflecting functional impairment or tubular damage [4-6]. One would assume that any observed biomark-

\section{KARGER}

(c) 2016 S. Karger AG, Basel

E-Mail karger@karger.com

www.karger.com/nef
Selected paper from a presentation at the 2016 AKI and CRRT UABUCSD O'Brien Center Symposium, San Diego, Calif., USA, February 16,2016 . This symposium was supported in part from a $\mathrm{Na}$ tional Institutes of Health grant for the UAB-UCSD O'Brien Center for Acute Kidney Injury Research (P30 DK079337). 


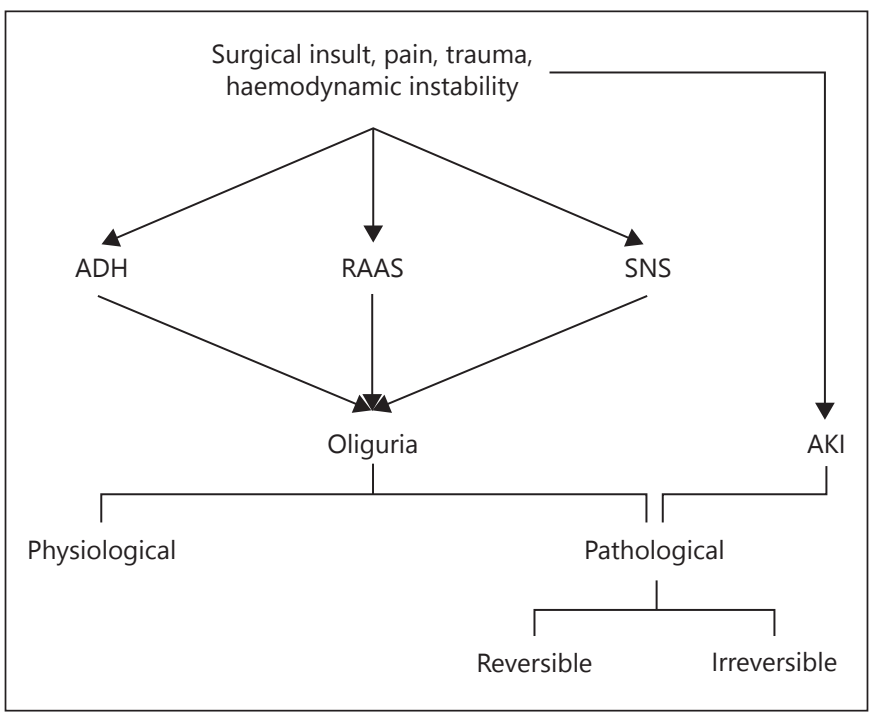

Fig. 1. Pathophysiological mechanisms causing oliguria. $\mathrm{ADH}=$ Antidiuretic hormone; RAAS = renin angiotensin aldosterone system; SNS = sympathetic nerve system; AKI = acute kidney injury.

recent guidelines, there is little justification for equality between these very different measures of renal function, neither in terms of the underlying physiology nor in the observed associations with clinical outcomes such as dialysis or death [8-10]. Whereas creatinine may roughly represent the glomerular filtration rate (GFR) in stable patients, urinary output changes may occur as a physiological response, as an indicator of stress, and as an indicator of failing glomerular filtration (fig. 1). Oliguria as a physiological response reflects conditions associated with antidiuresis due to hypovolemia. Triggered by the antidiuretic hormone $(\mathrm{ADH})$, the release of which is regulated by serum osmolarity, urinary osmolarity may reach values up to $1,400 \mathrm{mOsmol} / \mathrm{l}$ associated with respective reduction in urinary output in healthy humans. Hypothetically, if we assume a daily solute load of $700 \mathrm{mOsmol}$, then daily urinary output may be as low as $500 \mathrm{ml}$ (i.e. $0.28 \mathrm{ml} / \mathrm{kg} / \mathrm{h}$ in a $70 \mathrm{~kg}$ person). Earlier studies showed that $30-60 \mathrm{~h}$ of food and water fasting resulted in a maximally concentrated urine of less than $20 \mathrm{ml} / \mathrm{h}$ [11]. Therefore, AKI stage 1 criteria maybe be reached through normal physiological mechanisms, which has been demonstrated in a study investigating the urinary output of junior physicians while on call [12]. Therefore, the presence of oliguria may be misleading in that it may reflect a normal physiological response or may be indicative of a transient haemodynamic disturbance and not necessarily indicative of significant tubular injury. Indeed, severe tu- bular injury may not be apparent initially as oliguria given that concentrating ability is disturbed. Under such circumstances, urine flow reflects GFR and oliguria will not be apparent until GFR has fallen significantly. ADH release, however, may also occur by several nonosmotic stimuli including hypovolemia, pain, stress, surgery and trauma, where antidiuresis may be enhanced by the stimulation of the sympathetic nerve system and the reninangiotensin-aldosterone system.

In hospitalized patients, especially in those admitted to the intensive care unit (ICU), overt dehydration is unlikely. However, other nonosmotic triggers of $\mathrm{ADH}$ release and oliguria commonly occur including biological stress (e.g. surgery), nausea, pain and new acute haemodynamic instability. Some, but not all of these conditions, may be risk factors for the development of biochemical AKI, so while the presence of early oliguria should prompt evaluation of AKI risk, it does not necessarily imply that renal parenchymal injury has occurred. Based on these considerations, it is easy to understand why an increasing severity of oliguria (as defined by an increased period of oliguria for stage $2 \mathrm{AKI}$ and a lower threshold of $0.3 \mathrm{ml} /$ $\mathrm{kg} / \mathrm{h}$ for stage $3 \mathrm{AKI}$ ) is more clearly associated with hospital mortality $[8,13]$ rather than with, for example, the need for dialysis. An analysis of 14,536 critically ill patients from the Simplified Acute Physiology Score (SAPS) 3 cohort demonstrated that mortality in less severe AKI as defined by urinary output is generally lower than when solely defined by a rise in creatinine [8]. The highest mortality in each stage of AKI, however, is observed in those patients who fulfill both criteria simultaneously (table 1). The same relationship was reported in a large single-centre cohort of around 32,000 patients, where the presence of both oliguria and rise in serum creatinine was associated with worse outcomes than the same stage of AKI defined by either criteria alone [9]. Macedo et al. [13] demonstrated a mortality of nearly $9 \%$ in patients whose AKI was represented only by oliguria, whereas dialysis requirement was low around $2 \%$. This was completely different in patients with AKI based on rises in serum creatinine, which showed about the same rates in mortality and the need of dialysis of around 15\%. A few studies have investigated the question as to whether duration of oliguria may be more predictive for the development of AKI in critically ill patients. Prowle et al. [14] found that only oliguria lasting for more than $12 \mathrm{~h}$ provides significant prediction of the development of AKI stage 2. However, creatinine-defined AKI stage 2 frequently occurred without oliguria of this duration, while shorter duration of oliguria was common and often did not lead to the devel- 
Table 1. Hospital mortality of AKI stage according to AKIN criteria

\begin{tabular}{lllll}
\hline AKIN & $\begin{array}{l}\text { Creatinine or urinary } \\
\text { output criterion } \\
(\mathrm{SD}), \%(\mathrm{n})\end{array}$ & $\begin{array}{l}\text { Urinary output } \\
\text { criterion } \\
\text { only, \% (n) }\end{array}$ & $\begin{array}{l}\text { Creatinine criterion } \\
\text { only, \% (n) }\end{array}$ & $\begin{array}{l}\text { Creatinine and urinary } \\
\text { output criterion, } \\
\%(\mathrm{n})\end{array}$ \\
\hline Normal & $15.9(10,263)$ & $17.9(10,816)$ & $18.1(11,623)$ & $16.0(9,178)$ \\
Stage 1 & $34.5(1,077)$ & n.a. & $40.3(1,463)$ & n.a. \\
Stage 2 & $29.0(1,033)$ & $29.0(941)$ & $50.0(202)$ & $57.1(21)$ \\
Stage 3 & $41.2(1,983)$ & $41.0(1,837)$ & $52.7(262)$ & $63.8(116)$ \\
\hline
\end{tabular}

Hospital mortality rates were calculated separately for 14,536 patients from the SAPS 3 cohort according to their urinary output or their serum creatinine changes alone and the combination of both criteria (number of patients in each category given in brackets). Detailed methods are reported in Joannidis et al. [8]. Data for the combination of creatinine and urinary output criteria were not included in the original publication $[8] . \mathrm{SD}=$ Standard definition; n.a. = not available.

opment of biochemical AKI. Moreover, the prediction of AKI by urinary output varied by the patient cohort with the performance being better in medical than in surgical patients. In septic shock, a duration of at least $5 \mathrm{~h}$, however, appears to be a good predictor of AKI [15]. Finally, Md Ralib et al. [16] found a correlation between the volume of urinary output and duration of oliguria which suggested that a lower threshold of $0.3 \mathrm{ml} / \mathrm{kg} / \mathrm{h}$ should be used, if the 6-hour observation interval is used as a minimum for the definition of stage of AKI. Also in the study from Koyner et al. [17] patients with progressing AKI were mostly oliguric.

Given the increased risk for mortality associated with AKI, it is easy to understand why those patients who fulfill both urine output and serum creatinine criteria for higher AKI stages do worse, which probably represents stress and impairment of renal function coupled with a significant fall in GFR manifesting as oligoanuria [9].

\section{Urinary Chemistry and the Assessment of Oliguria}

The main chemical tests that may be performed on the urine of a patient with AKI include the fractional excretion of sodium (FENa) and urea as well as urinary estimation of creatinine. Although measures such as the urine:plasma creatinine ratio and the serum urea:creatinine ratio have been used to try to differentiate between AKI secondary to volume deplete states and intrinsic disease, results are inconsistent [18]. The urinary sodium has been used as an indicator of a 'pre-renal' aetiology for renal dysfunction, given the avid sodium reabsorption by the renal tubules in volume deplete states with a urinary sodium value of 10-20 $\mathrm{mmol} / \mathrm{l}$ suggestive of a haemodynamically reversible cause of renal dysfunction. A value of $>40 \mathrm{mmol} / \mathrm{l}$, however, is classically referred to as being indicative of established, not rapidly reversible, tubular injury. However, there is little to substantiate this in the literature particularly within the critical care environment. Indeed, the currently available data suggest that measurement of the urinary sodium has little or no diagnostic or prognostic utility within this population [19]. The FENa, which measures the percentage of filtered sodium that is excreted in the urine, has also been touted as a test to differentiate between acute tubular necrosis (ATN) and other causes of AKI with an FENa $>1 \%$ observed in ATN. However, the measurement of the FENa is also subject to error particularly in the critically ill where loop diuretics, for example, are often used and are, unsurprisingly, associated with an FENa in excess of $1 \%$ regardless of volume state. Also values of $<1 \%$ have been observed in many conditions associated with parenchymal renal disease as well as in sepsis [20] and the FENa may be $>1 \%$ when pre-renal disease is present in sodium-wasting states such as in chronic kidney disease. As such, it is of little use in isolation and results should be viewed with caution. Calculated in a similar fashion, the fractional excretion of urea (FEUrea) has been proposed as a superior test given the lack of a significant effect of diuretics that may have been administered, with an FEUrea $<35 \%$ indicative of a prerenal cause. However, interpretation remains difficult in the critically ill [21], especially in sepsis where a FEUrea $<35 \%$ was found in $63 \%$ of patients and discrimination between transitory and intrinsic AKI was negligible (area under the curve (AUC) 0.36) [20]. However, all septic patients who were classified as AKI stage 3 by oliguria presented with an FEUrea $<20 \%$ (table 2) [20]. 


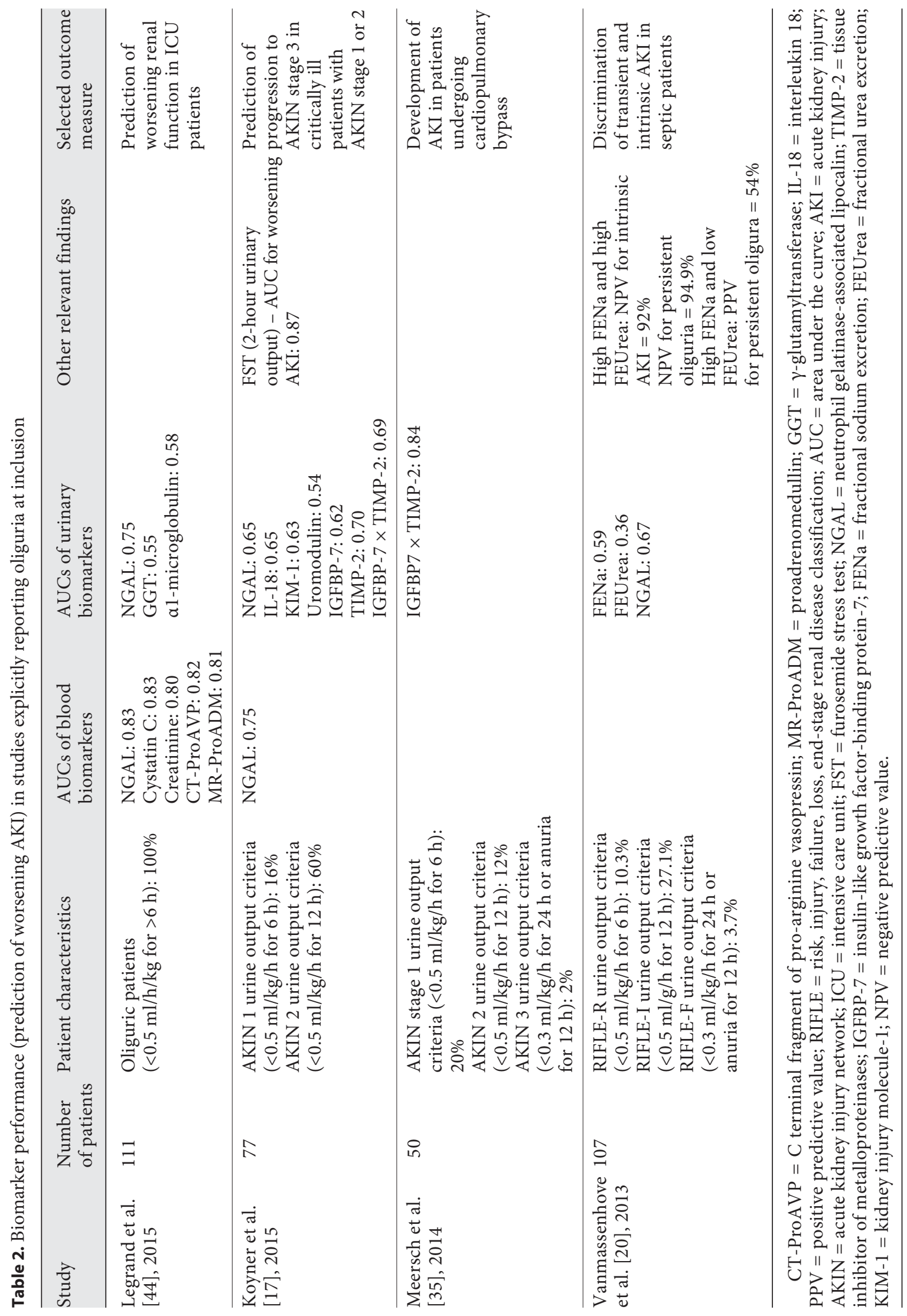




\section{Furosemide Stress Test}

In attempting to further define the diagnostic properties of oliguria, the furosemide stress test (FST) as described by Chawla et al. [22] may be seen as a functional test. A urine volume of $<200 \mathrm{ml}$ in the first $2 \mathrm{~h}$ after 1.0 $1.5 \mathrm{mg} / \mathrm{kg}$ furosemide was demonstrated as an ideal cutoff for predicting progressive AKI with a sensitivity of $87.1 \%$ and a specificity of $84.1 \%$. They demonstrated that volume-replete patients responding to a dose of furosemide with increased urine output were at lower risk of progression to higher stages of AKI [22]. Many of these patients were oliguric. Thus, the response to the FST in oliguria may be able to discriminate between a systemic stress response resulting in antidiuresis and truly impaired renal function, that is, AKI. Since loop diuretics have to be actively secreted into the proximal tubule by organic anion transporters to block sodium potassium chloride co-transporters, a positive response implies integrity of the renal tubule. The FST also demonstrated a significantly better performance than several urinary biomarkers tested to predict the progression of early AKI (table 2), need for renal replacement therapy (RRT) and inpatient death [17]. Interestingly, in the study from Koyner et al. [17] the combination of FST and biomarkers does not significantly improve risk stratification with regard to AKI progression, need for RRT or mortality in patients with AKI network (AKIN) stage 1 or 2 compared to FST alone. However, this finding might be influenced by the limited sample size, late timing of biomarker measurement and a potential source of confounding due to inclusion of patients with established AKI [17]. Conversely, the FST did show a higher AUC in terms of several outcome measures in patients with high biomarker levels (i.e. urine neutrophil gelatinase-associated lipocalin (NGAL) and urine tissue inhibitor of metalloproteinases 2 (TIMP-2) $\times$ insulin-like growth factor-binding protein-7 (IGFBP-7)), that is, high-risk patients [17]. Thus, the combination of functional biomarkers or tests and structural biomarkers might allow improved risk stratification.

\section{Biomarkers in Urine and Blood}

Biomarkers investigated in AKI can be stratified into markers primarily reflecting glomerular filtration (i.e. serum creatinine, serum cystatin C), glomerular integrity (i.e. albuminuria and proteinuria) or tubular stress, dysfunction or damage (e.g. NGAL, kidney injury mole-

Oliguria and Biomarkers cule-1 (KIM-1), $\mathrm{N}$-acetyl- $\beta$-D-glucosaminidase (NAG), liver fatty acid-binding protein (L-FABP), urinary cystatin C, TIMP-2, IGFBP-7) [23-25].

However, levels of several biomarkers are determined by more than one distinct factor, such as the rise of serum creatinine in AKI, which is not only caused by a drop in GFR but also by an altered secretion or backleak via tubular cells $[23,24]$. Also, microalbuminuria occurs due to an increased filtration of albumin caused by glomerular alterations as well as from decreased reabsorption resulting from tubular damage [23]. Besides these basically functional markers, several tubular specific enzymes and proteins considered to reflect ATN have been investigated as potential biomarkers for AKI, such as urinary NAG reflecting loss of tubular cell integrity [26] or KIM-1, which is upregulated in tubular epithelial cells as well as in immune cells [27-30]. In addition, NGAL, a protein expressed in neutrophils and renal tubular cells as well as in organs other than the kidney [31], has been investigated as biomarker in urine and plasma for prediction and prognosis of AKI [32]. Other biomarkers found to be useful for predicting AKI in various clinical settings like cardiac surgery or intensive care units include urinary Interleukin-18 [33] and L-FABP [34]. Finally, the combination of the 2 cell-cycle arrest markers TIMP-2 and IGFBP-7, currently the only FDA-approved diagnostic for AKI, was found to predict the development of AKI with an AUC of at least 0.8 when combined both in critically ill patients [25] and in patients following cardiac surgery [35]. A recent study, however, reported that urine levels of the latter markers may also be influenced by factors other than AKI [36].

The performance of the various biomarkers for prediction of AKI and outcome are outside of the scope of this review and are in detail summarized elsewhere [4, 5].

\section{Performance of Urinary Biomarkers with Respect to Urinary Output}

Whereas biomarkers of glomerular function (creatinine, cystatin C) and renal damage (NGAL) measured in serum are usually not influenced by physiologically reduced urinary output without AKI, the situation may be different for urinary biomarkers. As the concentration of biomarkers in urine is co-determined by the concentration or amount of urine itself, it seems reasonable to relate urinary biomarkers to urinary output, especially in a setting of rapidly changing GFR such as AKI. Several ap- 
proaches have been tried including the normalization of biomarkers to urinary creatinine [37], calculation of an average biomarker excretion rate or estimation of total biomarker excretion over a certain time period [38]. Normalization of a biomarker to urinary creatinine combines signals from cellular or structural injury with information about functional capacity (i.e. concentrating capacity and GFR) and thus might amplify the signal of a biomarker $[38,39]$. Moreover, the estimation of total biomarker excretion over a certain time period may reflect severity as well as the duration of injury.

Few studies reported absolute as well as creatininenormalized values of biomarkers in urine. According to Westhuyzen et al. [26], the normalization of urinary enzymes to urinary creatinine appears to improve the utility of tubular markers. Similar findings were reported by Prowle et al. [40] in a cohort of surgical patients for prediction of AKI when combining biomarkers of tubular injury (NGAL, $\pi-G S T$ ) and glomerular filtration (cystatin $\mathrm{C}$, hepcidin). Whereas the time-profile of the point estimates for (TIMP-2) $\times($ IGFBP-7) values shifted slightly when normalizing to urine creatinine, no relevant difference for diagnosing early AKI was detected in cardiac surgery patients [35]. Similarly, the overall pattern of the NGAL signal in children with AKI after cardiac surgery was unchanged when normalized to creatinine [41]. In contrast, Delanaye et al. [42] report that normalization of NGAL to creatinine improves intraindividual variations in healthy volunteers. Bojan et al. [43] compared absolute urinary NGAL concentrations, creatinine-normalized concentrations and absolute excretion rates in neonates and infants after cardiac surgery and found best performance for the prediction of severe AKI when NGAL was normalized to urinary creatinine. This is basically in accordance with the study from Ralib et al. [38] who compared the performance of absolute biomarker concentrations, normalization of biomarker concentrations to urinary creatinine concentration and biomarker excretion rate as well as estimated total biomarker excretion rate over $24 \mathrm{~h}$. They found that normalized concentrations performed best for the prediction of death, dialysis and the subsequent development of AKI, whereas absolute concentrations of injury biomarkers performed best in the diagnosis of AKI [38]. No benefit was shown when using excretion rate alone. Only for NGAL was an association between total estimated biomarker excretion over $24 \mathrm{~h}$ and different successive AKIN stages or long-term mortality detected [38]. However, since urinary creatinine concentration is not only determined by the urinary flow rate but also by the creatinine excretion rate, which changes over time during AKI, normalized biomarker levels are influenced by the urinary creatinine excretion [39]. As Ralib et al. [38] illustrate, the kinetics of creatinine excretion after AKI, determined by an abrupt GFR reduction and subsequent rise of plasma creatinine, might explain why normalization to urine creatinine improves performance of induced or preformed biomarkers mostly during incipient AKI, thus immediately after GFR reduction. Waikar et al. [39] also found that the variations in urinary creatinine excretion rates substantially affect normalized values of urinary biomarkers. They showed this potentially misleading effect of normalizing urinary biomarker levels to urinary creatinine in a simulation as well as in 2 groups of patients, that is, patients with AKI and patients after kidney transplantation. Consequently, the authors propose timed urine specimens as the most accurate method to estimate actual urinary creatinine excretion rate and to quantitate biomarkers [39]. In conclusion, relating urinary biomarkers to urinary output provides only limited benefit for current poorly performing biomarkers.

\section{Biomarkers of AKI in Oliguric Patients}

Does the combination of oliguria and biomarker measurement improve prediction of AKI? Generally, one would assume that in a cohort of oliguric patients prediction of AKI by biomarkers is significantly improved. Very few studies addressed this question by analyzing explicitly oliguric patients. The study by Meersch et al. [35] included only $20 \%$ of oliguric patients in AKI stage 1 and could demonstrate a very high prediction of AKI by urinary TIMP $2 \times$ IGFBP- 7 . In the above-mentioned study by Koyner et al. [17], 76\% of progressors to AKI stage 3 were oliguric. Despite that, prediction of AKI progression or RRT by several urinary biomarkers was substantially lower than by serum NGAL (table 2). Finally, Legrand et al. [44] exclusively included oliguric patients in their study. Despite a high pre-test probability of worsening renal function in this subgroup of patients, no biomarker performed better than serum creatinine to predict worsening of renal function. Nevertheless, plasma NGAL, Proadrenomedullin (MR-ProADM) and cystatin C had good performance (table 2) [44]. Although this study illustrates that not all episodes of oliguria result in a sustained decrease in GFR or AKI, the comparison of biomarkers to serum creatinine, a parameter that also substantially defines the outcome, limits the relevance of these findings. Interestingly, the finding that all 
biomarkers show higher negative predictive values (NPVs) than positive predictive values for AKI, suggests that they might especially be useful to rule out AKI in oliguria [44].

\section{Conclusion}

In conclusion, oliguria and biomarker signals are clearly confounded due to several mechanisms, which are relevant in both pathological as well as physiological states. Antidiuresis or oliguria can influence concentrations of particular AKI biomarkers. Moreover, a significant confounding factor in studies is the 'gold-standard' problem of oliguria being both an inclusion criteria and end point. Currently, clinicians are left with an approach that includes searching for and, if necessary and possible, treating physiological causes oliguria as well as starting serial monitoring of serum creatinine. Ensuring strict euvolemia, a FST may be considered to discriminate functional oliguria and reversible AKI from severe AKI. Biomarkers of function and damage may be helpful if available. A future area of research might be to evaluate the NPV of biomarkers for AKI, which may prove especially useful in triaging patients at risk of AKI and not exposing patients who are 'physiologically oliguric' to an array of further investigation and potential unnecessary treatments.

\section{Disclosure Statement}

G.F.L. reports no conflicts of interest with regard to this publication. M.J. and L.G.F. received speaker's honoraria from Astute Medical, Fresenius and Ortho Clinical Diagnostics.

\section{References}

1 Heberden W: Commentaries on the History and Cure of Diseases. London, Payne and Foss, 1816.

2 Bellomo R, Ronco C, Kellum JA, Mehta RL, Palevsky P: Acute renal failure - definition, outcome measures, animal models, fluid therapy and information technology needs: the second international consensus conference of the acute dialysis quality initiative (ADQI) group. Crit Care 2004;8:R204R212.

3 Macedo E, Malhotra R, Claure-Del Granado R, Fedullo P, Mehta RL: Defining urine output criterion for acute kidney injury in critically ill patients. Nephrol Dial Transplant 2011;26:509-515

-4 Vanmassenhove J, Vanholder R, Nagler E, Van Biesen W: Urinary and serum biomarkers for the diagnosis of acute kidney injury: an in-depth review of the literature. Nephrol Dial Transplant 2013;28:254-273.

$\checkmark 5$ Ho J, Tangri N, Komenda P, Kaushal A, Sood M, Brar R, Gill K, Walker S, MacDonald $\mathrm{K}$, Hiebert BM, Arora RC, Rigatto C: Urinary, plasma, and serum biomarkers' utility for predicting acute kidney injury associated with cardiac surgery in adults: a meta-analysis. Am J Kidney Dis 2015;66:9931005.

6 Ostermann M, Joannidis M: Biomarkers for AKI improve clinical practice: no. Intensive Care Med 2015;41:618-622.

7 KDIGO Acute Kidney Injury Work Group: KDIGO clinical practice guideline for acute kidney injury. Kidney Int Suppl 2012;2:1138.

8 Joannidis M, Metnitz B, Bauer P, Schusterschitz N, Moreno R, Druml W, Metnitz PG: Acute kidney injury in critically ill patients classified by AKIN versus RIFLE using the SAPS 3 database. Intensive Care Med 2009;35: 1692-1702.

-9 Kellum JA, Sileanu FE, Murugan R, Lucko N, Shaw AD, Clermont G: Classifying AKI by urine output versus serum creatinine level. J Am Soc Nephrol 2015;26:2231-2238.

$>10$ Liangos O, Perianayagam MC, Vaidya VS, Han WK, Wald R, Tighiouart H, MacKinnon RW, Li L, Balakrishnan VS, Pereira BJ, Bonventre JV, Jaber BL: Urinary N-acetyl-beta(D)-glucosaminidase activity and kidney injury molecule-1 level are associated with adverse outcomes in acute renal failure. J Am Soc Nephrol 2007;18:904-912.

11 Chesley LC: Urea excretion at low urine volumes. The calculation of 'minimal' urea clearances. J Clin Invest 1938;17:119-123.

12 Solomon AW, Kirwan CJ, Alexander ND, Nimako K, Jurukov A, Forth RJ, Rahman TM; Prospective Analysis of Renal Compensation for Hypohydration in Exhausted Doctors (PARCHED) Investigators: Urine output on an intensive care unit: case-control study. BMJ 2010;341:c6761.

13 Macedo E, Malhotra R, Bouchard J, Wynn SK, Mehta RL: Oliguria is an early predictor of higher mortality in critically ill patients. Kidney Int 2011;80:760-767.

14 Prowle JR, Liu YL, Licari E, Bagshaw SM, Egi M, Haase M, Haase-Fielitz A, Kellum JA, Cruz D, Ronco C, Tsutsui K, Uchino S, Bellomo R: Oliguria as predictive biomarker of acute kidney injury in critically ill patients. Crit Care 2011;15:R172.

15 Leedahl DD, Frazee EN, Schramm GE, Dierkhising RA, Bergstralh EJ, Chawla LS, Kashani KB: Derivation of urine output thresholds that identify a very high risk of AKI in patients with septic shock. Clin J Am Soc Nephrol 2014;9:1168-1174.

-16 Md Ralib A, Pickering JW, Shaw GM, Endre $\mathrm{ZH}$ : The urine output definition of acute kidney injury is too liberal. Crit Care 2013; 17:R112.

17 Koyner JL, Davison DL, Brasha-Mitchell E, Chalikonda DM, Arthur JM, Shaw AD, Tumlin JA, Trevino SA, Bennett MR, Kimmel PL, Seneff MG, Chawla LS: Furosemide stress test and biomarkers for the prediction of AKI severity. J Am Soc Nephrol 2015;26: 2023-2031.

18 Rachoin JS, Daher R, Moussallem C, Milcarek B, Hunter K, Schorr C, Abboud M, Henry P, Weisberg LS: The fallacy of the BUN:creatinine ratio in critically ill patients. Nephrol Dial Transplant 2012;27:2248-2254.

19 Pons B, Lautrette A, Oziel J, Dellamonica J, Vermesch R, Ezingeard E, Mariat C, Bernardin G, Zeni F, Cohen Y, Tardy B, Souweine B, Vincent F, Darmon M: Diagnostic accuracy of early urinary index changes in differentiating transient from persistent acute kidney injury in critically ill patients: multicenter cohort study. Crit Care 2013;17:R56

20 Vanmassenhove J, Glorieux G, Hoste E, Dhondt A, Vanholder R, Van Biesen W: Urinary output and fractional excretion of sodium and urea as indicators of transient versus intrinsic acute kidney injury during early sepsis. Crit Care 2013;17:R234.

21 Darmon M, Vincent F, Dellamonica J, Schortgen F, Gonzalez F, Das V, Zeni F, Brochard L, Bernardin G, Cohen Y, Schlemmer B: Diagnostic performance of fractional excretion of urea in the evaluation of critically ill patients with acute kidney injury: a multicenter cohort study. Crit Care 2011;15:R178. 
-22 Chawla LS, Davison DL, Brasha-Mitchell E, Koyner JL, Arthur JM, Shaw AD, Tumlin JA, Trevino SA, Kimmel PL, Seneff MG: Development and standardization of a furosemide stress test to predict the severity of acute kidney injury. Crit Care 2013;17:R207.

-23 Charlton JR, Portilla D, Okusa MD: A basic science view of acute kidney injury biomarkers. Nephrol Dial Transplant 2014;29:13011311.

-24 van Veldhuisen DJ, Ruilope LM, Maisel AS, Damman K: Biomarkers of renal injury and function: diagnostic, prognostic and therapeutic implications in heart failure. Eur Heart J 2015;pii:ehv588.

25 Kashani K, Al-Khafaji A, Ardiles T, Artigas A, Bagshaw SM, Bell M, Bihorac A, Birkhahn R, Cely CM, Chawla LS, Davison DL, Feldkamp T, Forni LG, Gong MN, Gunnerson KJ, Haase M, Hackett J, Honore PM, Hoste EA, JoannesBoyau O, Joannidis M, Kim P, Koyner JL, Laskowitz DT, Lissauer ME, Marx G, McCullough PA, Mullaney S, Ostermann M, Rimmele T, Shapiro NI, Shaw AD, Shi J, Sprague AM, Vincent JL, Vinsonneau C, Wagner L, Walker MG, Wilkerson RG, Zacharowski K, Kellum JA: Discovery and validation of cell cycle arrest biomarkers in human acute kidney injury. Crit Care 2013;17:R25.

26 Westhuyzen J, Endre ZH, Reece G, Reith DM, Saltissi D, Morgan TJ: Measurement of tubular enzymuria facilitates early detection of acute renal impairment in the intensive care unit. Nephrol Dial Transplant 2003;18:543-551.

-27 Ichimura T, Brooks CR, Bonventre JV: Kim1/Tim-1 and immune cells: shifting sands. Kidney Int 2012;81:809-811.

28 Xiao S, Zhu B, Jin H, Zhu C, Umetsu DT, DeKruyff RH, Kuchroo VK: Tim-1 stimulation of dendritic cells regulates the balance between effector and regulatory $\mathrm{T}$ cells. Eur J Immunol 2011;41:1539-1549.

29 Ichimura T, Hung CC, Yang SA, Stevens JL, Bonventre JV: Kidney injury molecule-1: a tissue and urinary biomarker for nephrotoxicant-induced renal injury. Am J Physiol Renal Physiol 2004;286:F552-F563.

30 Han WK, Bailly V, Abichandani R, Thadhani $\mathrm{R}$, Bonventre JV: Kidney injury molecule-1 (KIM-1): a novel biomarker for human renal proximal tubule injury. Kidney Int 2002;62: 237-244.

31 Paragas N, Qiu A, Hollmen M, Nickolas TL, Devarajan P, Barasch J: NGAL-siderocalin in kidney disease. Biochim Biophys Acta 2012; 1823:1451-1458.

32 Haase M, Bellomo R, Devarajan P, Schlattmann P, Haase-Fielitz A; NGAL Meta-Analysis Investigator Group: Accuracy of neutrophil gelatinase-associated lipocalin (NGAL) in diagnosis and prognosis in acute kidney injury: a systematic review and meta-analysis. Am J Kidney Dis 2009;54:1012-1024.

-33 Liu Y, Guo W, Zhang J, Xu C, Yu S, Mao Z, Wu J, Ye C, Mei C, Dai B: Urinary interleukin 18 for detection of acute kidney injury: a meta-analysis. Am J Kidney Dis 2013;62:10581067.

34 Susantitaphong P, Siribamrungwong M, Doi K, Noiri E, Terrin N, Jaber BL: Performance of urinary liver-type fatty acid-binding protein in acute kidney injury: a meta-analysis. Am J Kidney Dis 2013;61:430-439.

35 Meersch M, Schmidt C, Van Aken H, Martens S, Rossaint J, Singbartl K, Gorlich D, Kellum JA, Zarbock A: Urinary TIMP-2 and IGFBP7 as early biomarkers of acute kidney injury and renal recovery following cardiac surgery. PLoS One 2014;9:e93460.

- 36 Bell M, Larsson A, Venge P, Bellomo R, Martensson J: Assessment of cell-cycle arrest biomarkers to predict early and delayed acute kidney injury. Dis Markers 2015;2015: 158658.

-37 Nickolas TL, O’Rourke MJ, Yang J, Sise ME, Canetta PA, Barasch N, Buchen C, Khan F, Mori K, Giglio J, Devarajan P, Barasch J: Sensitivity and specificity of a single emergency department measurement of urinary neutrophil gelatinase-associated lipocalin for diagnosing acute kidney injury. Ann Intern Med 2008;148:810-819.

38 Ralib AM, Pickering JW, Shaw GM, Devarajan P, Edelstein CL, Bonventre JV, Endre ZH: Test characteristics of urinary biomarkers depend on quantitation method in acute kidney injury. J Am Soc Nephrol 2012;23:322-333.

39 Waikar SS, Sabbisetti VS, Bonventre JV: Normalization of urinary biomarkers to creatinine during changes in glomerular filtration rate. Kidney Int 2010;78:486-494.

40 Prowle JR, Calzavacca P, Licari E, Ligabo EV, Echeverri JE, Bagshaw SM, Haase-Fielitz A, Haase M, Ostland V, Noiri E, Westerman M, Devarajan P, Bellomo R: Combination of biomarkers for diagnosis of acute kidney injury after cardiopulmonary bypass. Ren Fail 2015; 37:408-416.

41 Mishra J, Dent C, Tarabishi R, Mitsnefes MM, Ma Q, Kelly C, Ruff SM, Zahedi K, Shao M, Bean J, Mori K, Barasch J, Devarajan P: Neutrophil gelatinase-associated lipocalin (NGAL) as a biomarker for acute renal injury after cardiac surgery. Lancet 2005;365:12311238.

42 Delanaye P, Rozet E, Krzesinski JM, Cavalier E: Urinary NGAL measurement: biological variation and ratio to creatinine. Clin Chim Acta 2011;412:390.

43 Bojan M, Vicca S, Lopez-Lopez V, Mogenet A, Pouard P, Falissard B, Journois D: Predictive performance of urine neutrophil gelatinase-associated lipocalin for dialysis requirement and death following cardiac surgery in neonates and infants. Clin J Am Soc Nephrol 2014;9:285-294.

44 Legrand M, Jacquemod A, Gayat E, Collet C, Giraudeaux V, Launay JM, Payen D: Failure of renal biomarkers to predict worsening renal function in high-risk patients presenting with oliguria. Intensive Care Med 2015;41: 68-76. 